\title{
Application of grey correlation method to evaluate potential groundwater recharge sites
}

Published online: 9 February 2006

(C) Springer-Verlag 2006

\begin{abstract}
Artificial recharge is a practical tool available for increasing the groundwater storage capacity. The efficiency of artificial recharge is related to various hydrogeological factors of the target area. In this study, a variable saturated groundwater flow model, FEMWATER, was used to evaluate the arrival times of recharged water that infiltrates from an artificial recharge pond to the groundwater table under various hydrogeological conditions. Forty-five arrival times were generated by FEMWATER. The relationships between the arrival times and hydrogeological factors used in the simulation of FEMWATER were analyzed by the grey correlation method. The results show the order of importance of the factors as they influence the arrival time. In order from high to low importance, they are $\alpha, D_{\mathrm{g}}, \theta_{\mathrm{e}}, D_{\mathrm{p}}, K_{\mathrm{S}}$ and $\beta . D_{\mathrm{g}}$ and $D_{\mathrm{p}}$ are interpreted as the potential for movement of the recharge water; $\theta_{\mathrm{e}}$ is the water storage capacity of soil, and $K_{\mathrm{S}}$ represents the ability of soil to transport water. $\alpha$ and $\beta$ describe the characteristic curve of the unsaturated soil. The method was applied to evaluate a suitable site for artificial recharge in the Yun-Lin area. Grey correlation analysis was performed to obtain the grey correlation grade using the minimum arrival time as a reference sequence. An index is proposed herein to determine the recharge efficiency of 20 sampling sites. A contour mapping of index values at the 20 sampling sites identified three areas for artificial aquifer recharge in Yun-Lin. Area A in the upper plain is considered more appropriate for groundwater recharge than areas $\mathrm{B}$ and $\mathrm{C}$ in the coast.
\end{abstract}

H. S. Gau · C. Y. Hsieh

Department of Environmental Engineering and Science, Tajen Institute of Technology, Ping-Tung, 907 Taiwan, R.O.C

C. W. Liu ( $\square)$

Department of Bioenvironmental Systems Engineering, National Taiwan University, Taipei, 106 Taiwan, R.O.C

E-mail: lcw@gwater.agec.ntu.edu.tw
Keywords Artificial recharge - Grey correlation analysis $\cdot$ Site selection $\cdot$ Numerical simulation

\section{Introduction}

The use of surface water during the wet season and groundwater during the dry season is one means of efficiently utilizing limited water resources. Artificial recharge methods can be applied to increase the groundwater storage capacity in the wet season. Todd (1980) and Bouwer (1996, 2002) introduced several artificial recharge techniques, such as well recharge, and the use of infiltration basin and seepage trenches. An effective artificial recharge method must suit site-specific conditions, including soil permeability, the properties of the unsaturated soil, geological structure, hydrological conditions, topography and land use. Recently, the photographic mapping has been used to determine the ambit of land use, the spread of soil types and the geological structure, based on satellite images, which have thus been used to identify potential recharge areas (Salama et al. 1994; Saraf and Choudhury 1998). Rastogi and Pandey (1998) compared the efficacy of artificial recharge basins with different shapes by finite element modeling. They pointed out that a rectangular artificial recharge basin can store more water in an aquifer than basins of other shapes. Moreover, Gau et al. (2001) investigated the effects of relevant hydrogeological factors, including the depth of the artificial recharge pond water, the hydraulic conductivity and the depth of the groundwater table, on the arrival time of the recharge water to the groundwater table. They concluded that an appropriate site for artificial recharge is not determined by only the hydraulic conductivity.

A suitable artificial recharge site must have highly permeable soil, with no impermeable layer, an unconfined aquifer and an absence of any contamination source (Bouwer 1996). Methods for estimating the rate or amount of groundwater recharge have been developed. The simple water balance model has been widely 
applied to estimating the amount of groundwater recharge, but any estimate made using this model is sensitive to the forest canopy parameters, and parameters in the soil moisture model, particularly the rooting depth, the fractional available water content, and the fractional field of drainable water (Finch 1998). Other simple soil models can also be used to estimate water recharge, by calculating how much water is potentially available for groundwater recharge from the differences among the measured rainfall, the estimated actual evapotranspiration and the soil moisture (Ragab et al. 1997; Chapman and Malone 2002). As well as the aforementioned physical models, the measured distribution of environmental tracers, ${ }^{3} \mathrm{H},{ }^{36} \mathrm{Cl}$ and chloride, in a soil water profile, have also been used to estimate the rate of movement of water in soil, to locate a groundwater aquifer (Eriksson and Khunakasem 1969; Sukhija et al. 1997; Cook and Robinson 2002).

All of the above methods are appropriate for estimating the recharge rate at a site where sufficient in situ data have been measured in the field. However, if no field data are available to estimate the recharge rate, then the use of results simulated using a groundwater model is an effective means of evaluating the feasibility of a site for artificial recharge. Many groundwater simulation models have been developed over the last 20 years for simulating the response of a groundwater head to surface infiltration (van Dam and Feddes 2000; Warrick 1991; Giao et al. 1999; Parlange et al. 1999). A variable saturation model is required to simulate the movement of the wetting front of recharge water from unsaturated soil to the saturated ground water aquifer. The recharge water contributes to the groundwater only if the wetting front reaches the groundwater table. Accordingly, the efficacy of an artificial recharge site can be measured by comparing the required arrival time of the wetting front at groundwater table.

Hydrogeological factors, including hydraulic conductivity, the depth of water in an artificial recharge pond, the depth of the groundwater table and the unsaturated soil characteristic curve, are required to simulate variable saturated groundwater flow. Some factors may be easily measured in the field, such as hydraulic conductivity, depth of water in the artificial recharge pond and depth of the groundwater table. Other factors, such as parameters that govern the characteristic curve of unsaturated soil, can only be determined with extra time and labor, and expensive instruments. Therefore, the hydrogeological factors that can be measured in the field depend on the budget of the project and the time available. The order of importance of these factors to the movement of recharge water must be established to determine the priority of these factors to be measured in the field.

In this work, the variable saturated groundwater model, FEMWATER, was used to simulate the arrival time of recharge water at the groundwater table and to determine the relationship between the arrival time and each hydrogeological factor. The order of importance of the hydrogeological factors to the recharge of ground water was evaluated by the grey correlation method (Deng 1989). The determined order of importance of the hydrogeological factors coupled with the grey correlation analysis was then applied to locate the optimal recharge site in Yun-Lin plain in Taiwan. The results help engineers not only to identify the important factors that need to be measured in the field, but also offer an effective means of evaluation in a preliminary screening of a groundwater recharge site.

\section{Materials and methods}

\subsection{Numerical simulation model}

The arrival time of the recharged water front at the groundwater table is an important factor that governs groundwater recharge. Various methods can be used to determine the arrival time, including laboratory, field and numerical experiments. Laboratory and field experiments are expensive and time-consuming, so numerical experiments are conducted to simulate the movement of a wetting front and estimate the arrival time of artificial recharge water at the groundwater table.

The Richards' equation is commonly used to describe the movement of infiltration through an unsaturated zone of soils. It is given as follows (El-Hames and Richards 1995)

$C(h) \frac{\partial h}{\partial t}=\nabla \cdot[K(h) \cdot \nabla(h+z)]+q$,

where $C(h)$ represents the differential water capacity $(\partial \theta / \partial h)\left(\mathrm{L}^{-1}\right) ; \theta$ is the water content $\left(\mathrm{L}^{3} \mathrm{~L}^{-3}\right) ; h$ is the water pressure head; $t$ is the time (T); $K$ is the unsaturated hydraulic conductivity; $z$ is the potential head $(\mathrm{L})$, and $q$ is the source and/or sinks $\left(\mathrm{L}^{3} \mathrm{~L}^{-3} \mathrm{~T}^{-1}\right)$.

Many numerical groundwater models have been developed based on Richards' equation to simulate the distribution of pressure head and water content, or the saturation of unsaturated soil. In this work, a threedimensional finite element computer model, FEMWATER, was used to simulate density-dependent flow and transport in variably saturated media. (Lin et al. 1997) This model is incorporated into a visualized groundwater modeling system, GMS (EMRL 2003), which is adopted herein to perform a numerical experiment.

A homogenous and isotropic soil column of size $14 \mathrm{~m} \times 14 \mathrm{~m} \times 30 \mathrm{~m}$ and a pond of size $12 \mathrm{~m} \times 12 \mathrm{~m} \times 3 \mathrm{~m}$ on top of it, are considered in the numerical experiment (Fig. 1). The depth of water in the pond and the groundwater table is maintained at a constant level throughout the numerical simulation. Impermeable walls are set around the soil column and recharge water flow infiltrates vertically. The soil column is discretized into 2,790 prism elements with 1,936 nodes. The size of each prism element is $2 \mathrm{~m} \times 2 \mathrm{~m} \times 1 \mathrm{~m}$ (Fig. 1). 
Fig. 1 Soil column for modeling recharge test by FEMWATER in the numerical experiment

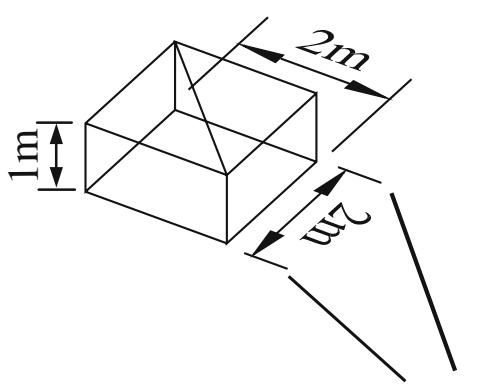

$10 \mathrm{~m} \times 10 \mathrm{~m} \times 3 \mathrm{~m}$

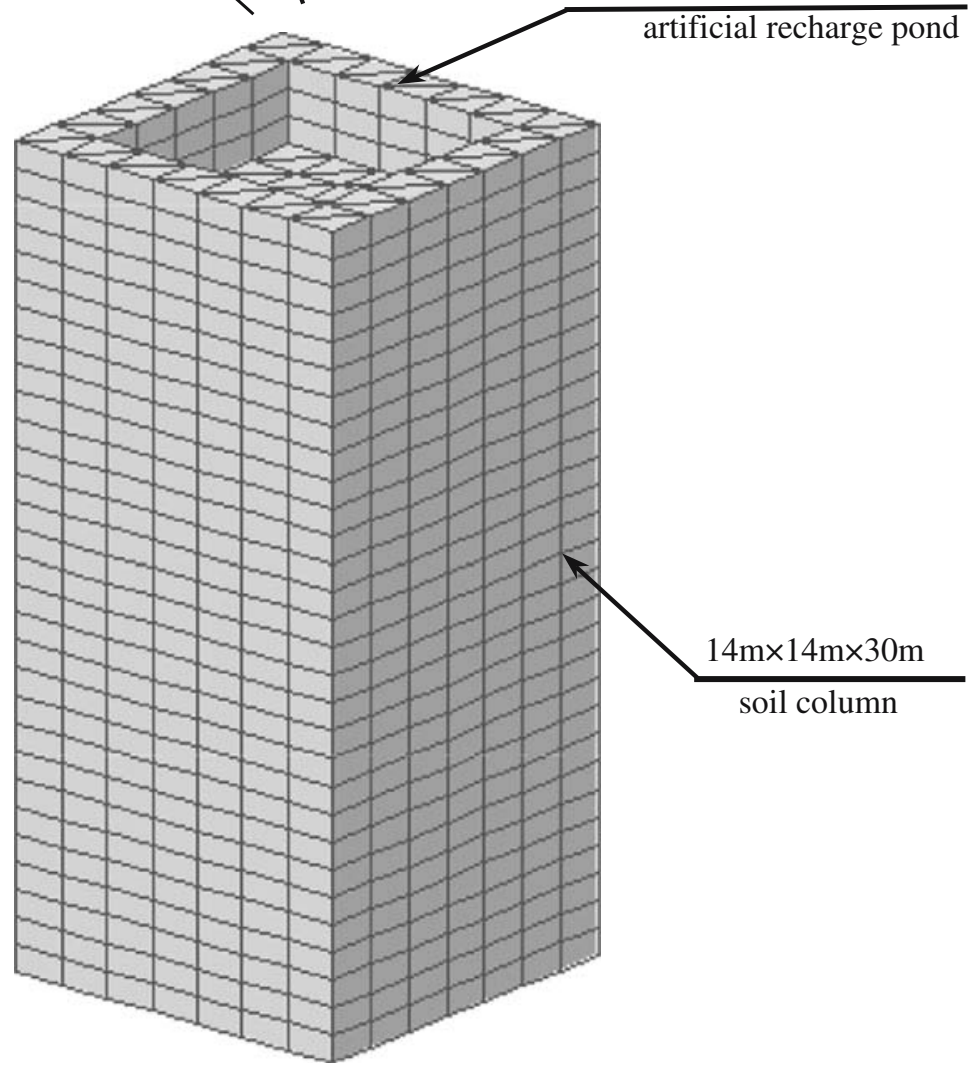

The characteristic curve of unsaturated soil is determined by the Mualem-van Genuchten model equations (van Genuchten 1980):

$$
\begin{aligned}
& S_{\mathrm{e}}=\left[1+(\alpha \psi)^{\beta}\right]^{1 / \beta-1}, \\
& K\left(S_{\mathrm{e}}\right)=K_{\mathrm{S}} \sqrt{S_{\mathrm{e}}}\left(1-\left(1-S_{\mathrm{e}}^{\beta / \beta-1}\right)^{1-1 / \beta}\right)^{2},
\end{aligned}
$$

where $K\left(S_{\mathrm{e}}\right) \quad\left(\mathrm{L} \mathrm{T}^{-1}\right)$ is the unsaturated hydraulic conductivity; $K_{\mathrm{S}}\left(\mathrm{L} \mathrm{T}^{-1}\right)$ is the saturated hydraulic conductivity; $\psi$ is the absolute value of the matrices potential $\left(\mathrm{M} \mathrm{T}^{-2} \mathrm{~L}^{-1}\right) ; S_{\mathrm{e}}=\frac{\theta-\theta_{\mathrm{r}}}{\theta_{\mathrm{s}}-\theta_{\mathrm{r}}}$ is the degree of saturation (dimensionless); $\theta$ is the water content $\left(\mathrm{L}^{3} \mathrm{~L}^{-3}\right)$; $\theta_{\mathrm{S}}$ is the saturated water content $\left(\mathrm{L}^{3} \mathrm{~L}^{-3}\right) ; \theta_{\mathrm{r}}$ is the residual water content $\left(\mathrm{L}^{3} \mathrm{~L}^{-3}\right)$, and $\alpha\left(\mathrm{L}^{-1}\right)$ and $\beta$ (dimensionless) are parameters obtained by curve fitting (Luckner et al. 1989). $\theta_{\mathrm{r}}$ is defined as the value of $\theta$ at which fluid flow in response to hydraulic gradients ceased, whereas $\theta_{\mathrm{s}}$ is measured experimentally.
The fitting parameters $\alpha$ and $\beta$ are used to describe the shape of the water-release curve. $\alpha$ is proportional to the reciprocal of the value of $\psi$ halfway between $\theta_{\mathrm{S}}$ and $\theta_{\mathrm{r}}$. Small $\alpha$ values represent little change in water content as $\psi$ becomes more negative, and are generally observed in fine-grained and unstructured soils. Large values of $\alpha$ indicate a rapid change in water content as some pores empty out under very small negative heads. They are typically found in sands or well-structured soils. The parameter $\beta$ specifies the steepness of the water-release curve. If $\beta$ is large, then the curve is steep, and the water content decreases quickly as $\psi$ becomes more negative. If $\beta$ is small, then the change in water content is slow (Hodnett and Tomasella 2002). Five soils, silty clay loam (SCL), yolo light clay (YLC), sand, loamy sand and loam, are selected as the materials in the simulated soil column. Table 1 presents the parameters of the five soil characteristics curves. Kao et al. (2001) experimentally measured the parameters of the first three soils. The 
Table 1 Mualem-van Genuchten parameters of the soil materials light clay, $S C$ sand clay

\begin{tabular}{llllll}
\hline $\begin{array}{l}\text { Soil } \\
\text { material type }\end{array}$ & $\begin{array}{l}\text { Saturated } \\
\text { hydraulic conductivity } \\
\left(K_{\mathrm{S}}\right)(\mathrm{m} / \text { days })\end{array}$ & $\begin{array}{l}\text { Residual } \\
\text { water content } \\
\left(\theta_{\mathrm{r}}\right)\end{array}$ & $\begin{array}{l}\text { Saturated } \\
\text { water content } \\
\left(\theta_{\mathrm{s}}\right)\end{array}$ & $\alpha(1 / \mathrm{m})$ & $\beta$ \\
\hline SCL & 0.0624 & 0.1000 & 0.4100 & 1.90 & 1.31 \\
YLC & 0.4320 & 0.2300 & 0.5500 & 3.60 & 1.90 \\
SAND & 2.4000 & 0.0500 & 0.5000 & 3.70 & 5.00 \\
LOAM & 0.2520 & 0.0776 & 0.4300 & 3.67 & 1.56 \\
SC & 0.0307 & 0.0993 & 0.3800 & 2.70 & 1.28 \\
\hline
\end{tabular}

other parameters were generated using the distribution functions suggested by Hubert et al. (1996).

Constant depths of pond water $\left(D_{\mathrm{p}}\right)$ of 1,2 and $3 \mathrm{~m}$ were maintained throughout the simulations. The depths between the bottom of the pond and the groundwater table $\left(D_{\mathrm{g}}\right)$ were also fixed at 10,20 and $30 \mathrm{~m}$. Other sources and sinks, including rainfall infiltration, the pumping well and evapotranspiration, were not considered herein. The initial pressure heads were set to $-0.5 \mathrm{~m}$ in all grids. Under the simulation conditions, a total of $45(3 \times 3 \times 5)$ cases were considered.

The FEMWATER outputs the simulated total head and pressure heads every hour. The results of the pressure heads were plotted as contours to trace the position of the zero-pressure. The contour of the zero pressure head intersected the groundwater table, and the arrival time of the recharged water front was determined accordingly.

\subsection{Grey correlation analysis}

A sensitivity analysis is conducted to evaluate the importance of the hydrological factors for the movement of recharge water. The traditional sensitivity analysis is a "change-one-factor-at-a-time method": one factor is varied while all others are fixed. However, the simplicity of the method may yield unreliable results and an inadequate conclusion because factors are uncertain (Deng 1996; Chang 2005). Deng (1989) presented a method of grey correlation analysis, which addresses some of the shortcomings of the traditional method. The basic concept of grey correlation analysis is to determine whether a relationship among a series of data is close, based on the degree of similarity among the geometric shapes of the data series' curves. Closer curves indicate a greater the correlation among the relative data series. The grey correlation grades are determined from the grey correlation coefficients, which measure the degree of similarity among sequences. The order of sensitivity of the hydrological factors to the movement of recharge water can then be determined based on the calculated grey correlation grades. The method has been extensively applied across many areas, such as auto control design, water resource development, hydroelectric generation scheduling and environmental management.
(Fung 2003; Yeh and Chen 2004; Liang 1999; Chang and Lin 1999).

\subsubsection{Data preprocessing}

Grey data processing must be performed before grey correlation coefficients can be calculated. A series of various units must be transformed to be dimensionless. Usually, each series is normalized by dividing the data in the original series by their average.

Let the original reference sequence and sequence for comparison be represented as $x_{\mathrm{o}}(k)$ and $x_{i}(k), i=1,2, \ldots$, $m ; k=1,2, \ldots, n$, respectively, where $m$ is the total number of factors to be considered, and $n$ is the total number of observation data. Data preprocessing converts the original sequence to a comparable sequence. Several methodologies of preprocessing data can be used in grey relation analysis, depending on the characteristics of the original sequence (Fung 2003). If the target value of the original sequence is "the-larger-the-better", then the original sequence is normalized as follows;

$x_{i}^{*}(k)=\frac{x_{i}(k)-\min x_{i}(k)}{\max x_{i}(k)-\min x_{i}(k)}$.

If it is "the-smaller-the-better", then the original sequence is normalized as follows;

$x_{i}^{*}(k)=\frac{\max x_{i}(k)-x_{i}(k)}{\max x_{i}(k)-\min x_{i}(k)}$.

However, if there is a specific target value, then the original sequence is normalized using,

$x_{i}^{*}(k)=1-\frac{\left|x_{i}(k)-\mathrm{OB}\right|}{\max \left\{\max x_{i}(k) \mathrm{OB}, \mathrm{OB}-\min x_{i}(k)\right\}}$,

where $\mathrm{OB}$ is the target value.

\subsubsection{Grey correlation coefficient and grey correlation grade}

After the data have been preprocessed, a grey correlation coefficient is determined using the preprocessed sequence. The grey correlation coefficient is defined as (Deng 1989; Fung 2003; Yeh and Chen 2004), 
$\gamma\left(x_{\mathrm{o}}^{*}(k), x_{i}^{*}(k)\right)=\frac{\Delta_{\min }+\xi \Delta_{\max }}{\Delta_{\mathrm{o} i}(k)+\xi \Delta_{\max }}$,

where $\xi$ is the distinguishing coefficient, $\xi \in(0,1)$. Generally $\xi$ is taken as 0.5 (Deng 1989). $\Delta_{\mathrm{o}} i(k)$ is the sequence of deviation of the reference sequence $x_{\mathrm{o}}^{*}(k)$ from the sequence $x_{i}^{*}(k)$ for comparison;

$\Delta_{\mathrm{o} i}(k)=\left|x_{\mathrm{o}}^{*}(k)-x_{i}^{*}(k)\right|, \Delta_{\max }=\max _{\forall j \in i} \max _{\forall k}\left|x_{\mathrm{o}}^{*}(k)-x_{j}^{*}(k)\right|$ and $\Delta_{\min }=\min _{\forall j \in i} \min _{\forall k}\left|x_{\mathrm{o}}^{*}(k)-x_{j}^{*}(k)\right|$. The grey correlation grade is an average of the grey correlation coefficients and is defined as (Deng 1989),

$\Gamma_{i}\left(x_{\mathrm{o}}^{*}, x_{i}^{*}\right)=\frac{1}{n} \sum_{k=1}^{n} \gamma\left(x_{\mathrm{o}}^{*}(k), x_{i}^{*}(k)\right)$.

Herein, the grey correlation grade represents the degree of correlation between the reference sequence and the sequence for comparison. If a particular sequence for comparison is more important to the reference sequence than other comparable sequences, then the grey correlation grade between that comparable sequence and reference sequence exceed the other grey correlation grades. If the comparable sequence is consistent with the reference sequence, then the grey correlation grade is close to unity. Grey relational analysis measures the absolute differences between sequences, and so can be used to measure the approximate correlation of sequences (Fung 2003).

\section{Results and discussion}

\subsection{Numerical experiment}

Figure 2 plots the simulated arrival times in the numerical experiment. The ordinate represents the arrival time of recharge water at the groundwater table. The abscissa represents the depth of the pond water. The solid line with rectangular, triangular and circular symbols represents the groundwater tables 10, 20 and $30 \mathrm{~m}$ underground, respectively. Four vertical solid lines divide the figure into five zones based on the type of soil. The results indicate that the arrival time increased with the depth of the groundwater table and fell as the depth of the pond water increased, regardless of the soil. Comparing the arrival times in different soils shows that the arrival time is shortest in the sand material and longest in the SCL material. The difference between the shortest and longest arrival times increases with the depth of the groundwater table.

The arrival time is used to evaluate the efficiency of artificial recharge. A short arrival time represents highly efficient artificial recharge because the pond water easily infiltrates the soil and recharges to groundwater aquifer. Conversely, a long arrival time represents a poor effi-

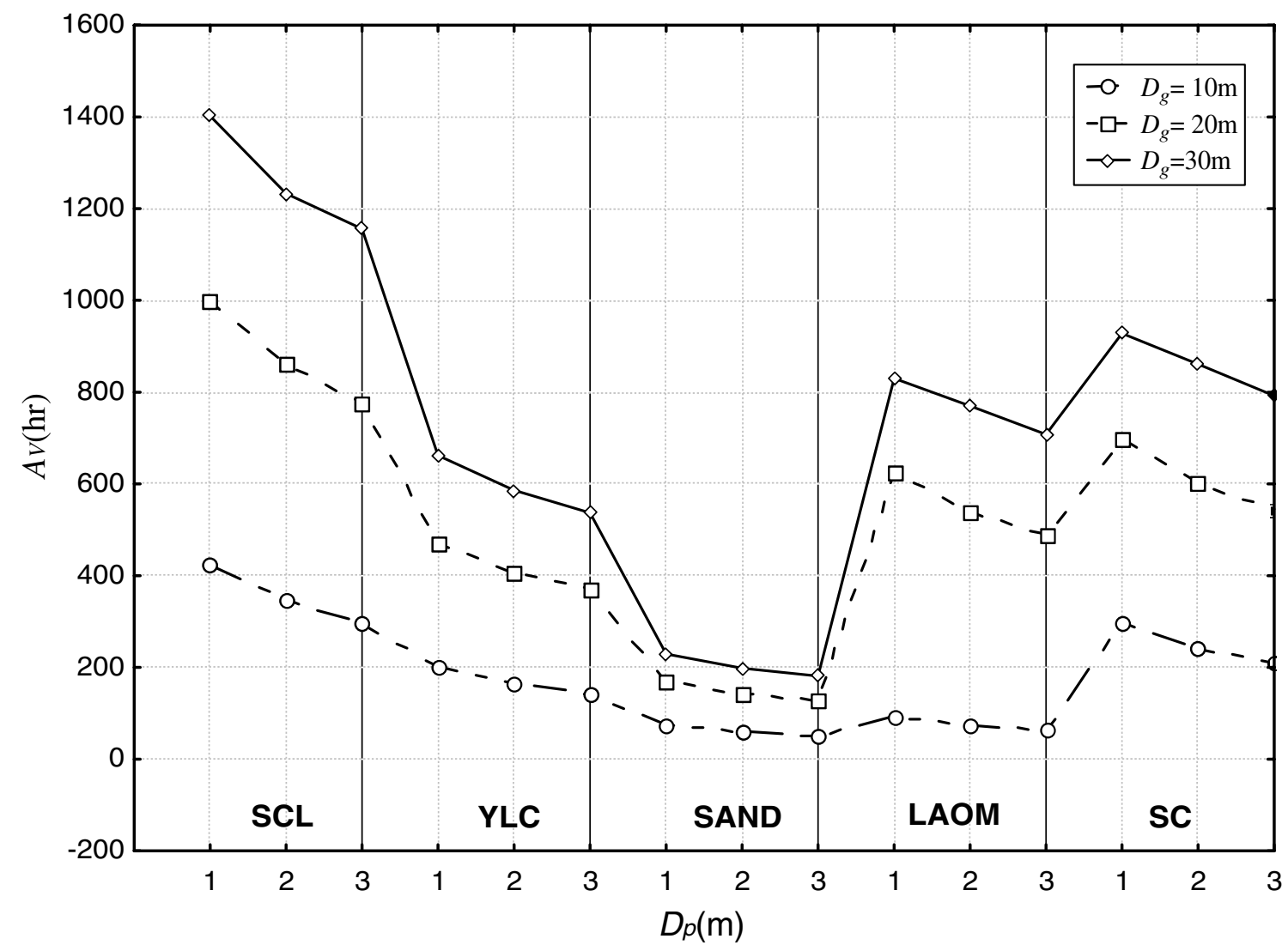

Fig. 2 Arrival time of recharge water $\left(A_{\mathrm{V}}\right)$ at groundwater table, calculated by FEMAWATER under different simulated conditions 
ciency of artificial recharge, because most of the infiltrated pond water is retained in the unsaturated zone and cannot quickly be replenished to the groundwater table. If the required arrival time exceeds the duration of the wet season, then no surface water is available for recharge in the dry season. Therefore, the arrival time is the key to locating an artificial recharge pond. Clearly, the results in Fig. 2 demonstrate that a suitable site for an artificial recharge pond has a shallow groundwater table, permeable soil like sand, and a deep pond water. Unfortunately, such conditions are not always available. For instance, a permeable soil may have a deep groundwater table. If a hydraulic engineer evaluates a potential site for an artificial recharge pond based solely on a single hydrogeological factor, such as the hydraulic conductivity of soil, an incorrect decision may be made. Hence, grey correlation analysis is useful for calculating the grey correlation grade of influential factors. With reference to the order of the grey correlation grade, the sensitivity of each factor to the movement of recharge

Table 2 Experimental factor values corresponding to factor levels

\begin{tabular}{|c|c|c|c|c|c|c|c|}
\hline \multirow{3}{*}{$\begin{array}{l}\text { Levels of } \\
\text { factors }\end{array}$} & \multicolumn{7}{|l|}{ Factors } \\
\hline & \multirow[t]{2}{*}{$D_{\mathrm{g}}(\mathrm{m})$} & \multirow[t]{2}{*}{$D_{\mathrm{p}}(\mathrm{m})$} & \multirow{2}{*}{$\begin{array}{l}\text { Soil } \\
\text { type }\end{array}$} & \multicolumn{4}{|c|}{ Property of soil } \\
\hline & & & & $\begin{array}{l}K_{\mathrm{S}} \\
(\mathrm{m} / \text { days })\end{array}$ & $\theta_{\mathrm{e}}$ & $\begin{array}{l}\alpha \\
(1 / \mathrm{m})\end{array}$ & $\beta$ \\
\hline 1 & 10 & 1 & SCL & 0.0624 & 0.3100 & 1.90 & 1.31 \\
\hline 2 & 20 & 2 & YLC & 0.4320 & 0.3200 & 3.60 & 1.90 \\
\hline 3 & 30 & 3 & SAND & 2.400 & 0.4500 & 3.70 & 5.00 \\
\hline 4 & & & LOAM & 0.2520 & 0.3524 & 3.67 & 1.56 \\
\hline 5 & & & $\mathrm{SC}$ & 0.0307 & 0.2807 & 2.70 & 1.28 \\
\hline
\end{tabular}

water is analyzed and an optimal site for constructing an artificial recharge pond can be determined without bias.

\subsection{Most influential factor}

Six influential factors are considered herein. Table 2 presents the influential factors and factor levels at which the effective water content, $\theta_{\mathrm{e}}$, is defined as $\theta_{\mathrm{e}}=\theta_{S}-\theta_{\mathrm{r}}$. Figure 3 displays the arrival times of recharge water $\left(A_{\mathrm{V}}\right)$ at the groundwater table for a total of 45 different factor levels. The arrival times of the 45 numerical runs are assigned to the original reference sequence $x_{A_{\mathrm{V}}}(k), k=1,2$, $\ldots, 45$. The six influential factors in 45 runs are set as the comparable sequence $x_{D_{\mathrm{g}}}(k), x_{D_{\mathrm{p}}}(k), x_{K_{\mathrm{S}}}(k), x_{\theta_{\mathrm{e}}}(k)$, $x_{\alpha}(k), x_{\beta}(k), k=1,2, \ldots, 45$.

Figure 4 is a scatter plot of the factors $\theta_{\mathrm{e}}, K_{\mathrm{S}}, \alpha$ and $\beta$ versus arrival time. The results indicate that the arrival time increases as the factors decrease. Figure 2 indicates that the arrival time increases with $D_{\mathrm{g}}$ and falls as $D_{\mathrm{p}}$ increases. A shorter arrival time generally corresponds to a higher artificial recharge. Thus, the arrival time is "the-smaller-the-better". The smaller-the-better method, Eq. 5, was applied to preprocess the data. The factor sequence $\theta_{\mathrm{e}}, K_{\mathrm{S}}, \alpha, \beta$ and $D_{\mathrm{p}}$ are "the-larger-the-better". Hence, the "the-larger-the-better" method, Eq. 4, was employed to the factors $\theta_{\mathrm{e}}, K_{\mathrm{S}}, \alpha, \beta$ and $D_{\mathrm{p}}$ for data preprocessing.

Figure 5 plots the results of data preprocessing. $x_{A_{\mathrm{V}}}^{*}(k)$ and $x_{i}^{*}(k), i=D_{\mathrm{g}}, D_{\mathrm{p}} \ldots \alpha, \beta$ denote the reference sequence and comparable sequence, respectively. The deviation sequences $\Delta_{A_{\mathrm{V}} D_{\mathrm{g}}}(1), \Delta_{A_{\mathrm{V}} D_{\mathrm{p}}}(1), \Delta_{A_{\mathrm{V}} K_{\mathrm{S}}}(1), \Delta_{A_{\mathrm{V}} \theta_{\mathrm{e}}}(1), \Delta_{A_{\mathrm{V}} \alpha}$ (1), $\Delta_{A_{\mathrm{V}} \beta}(1)$ are calculated as follows;

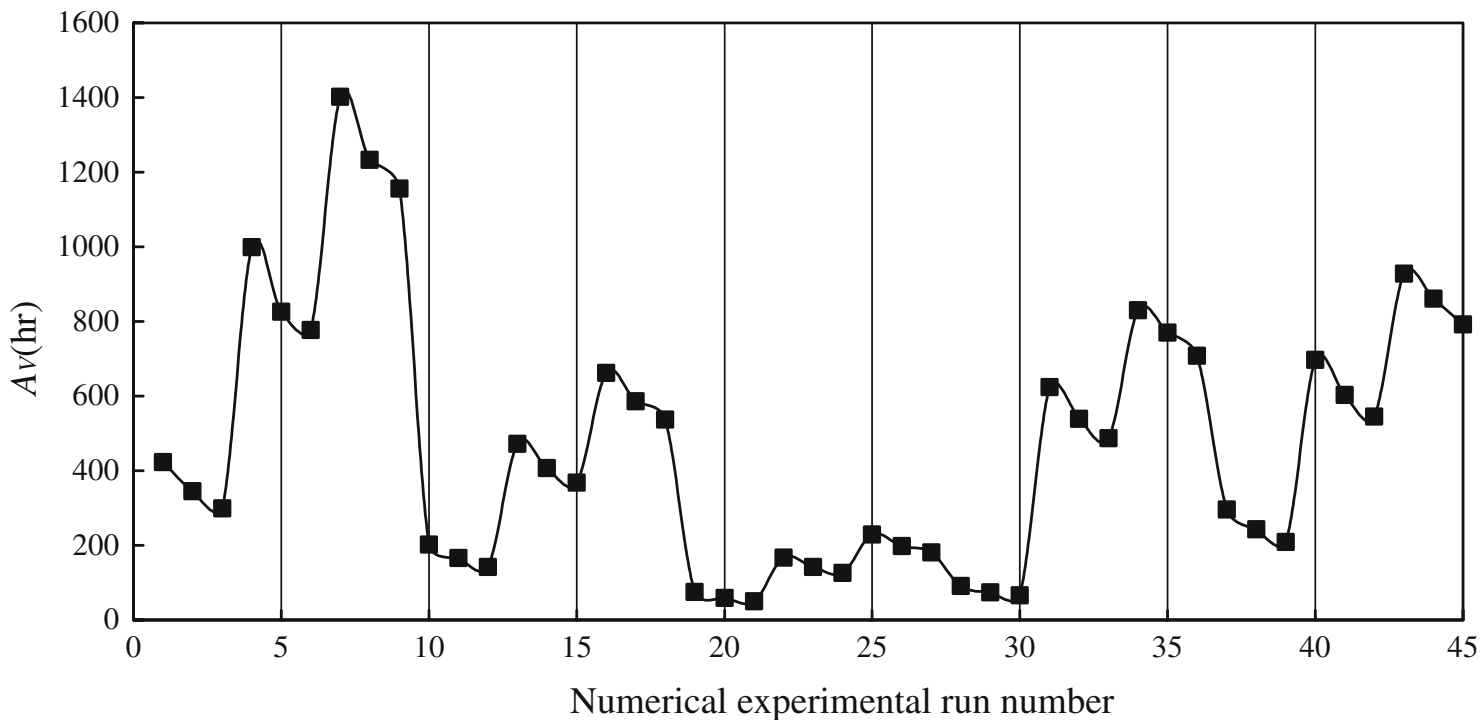

Fig. 3 Simulated arrival times of artificial recharge water at ground water table 


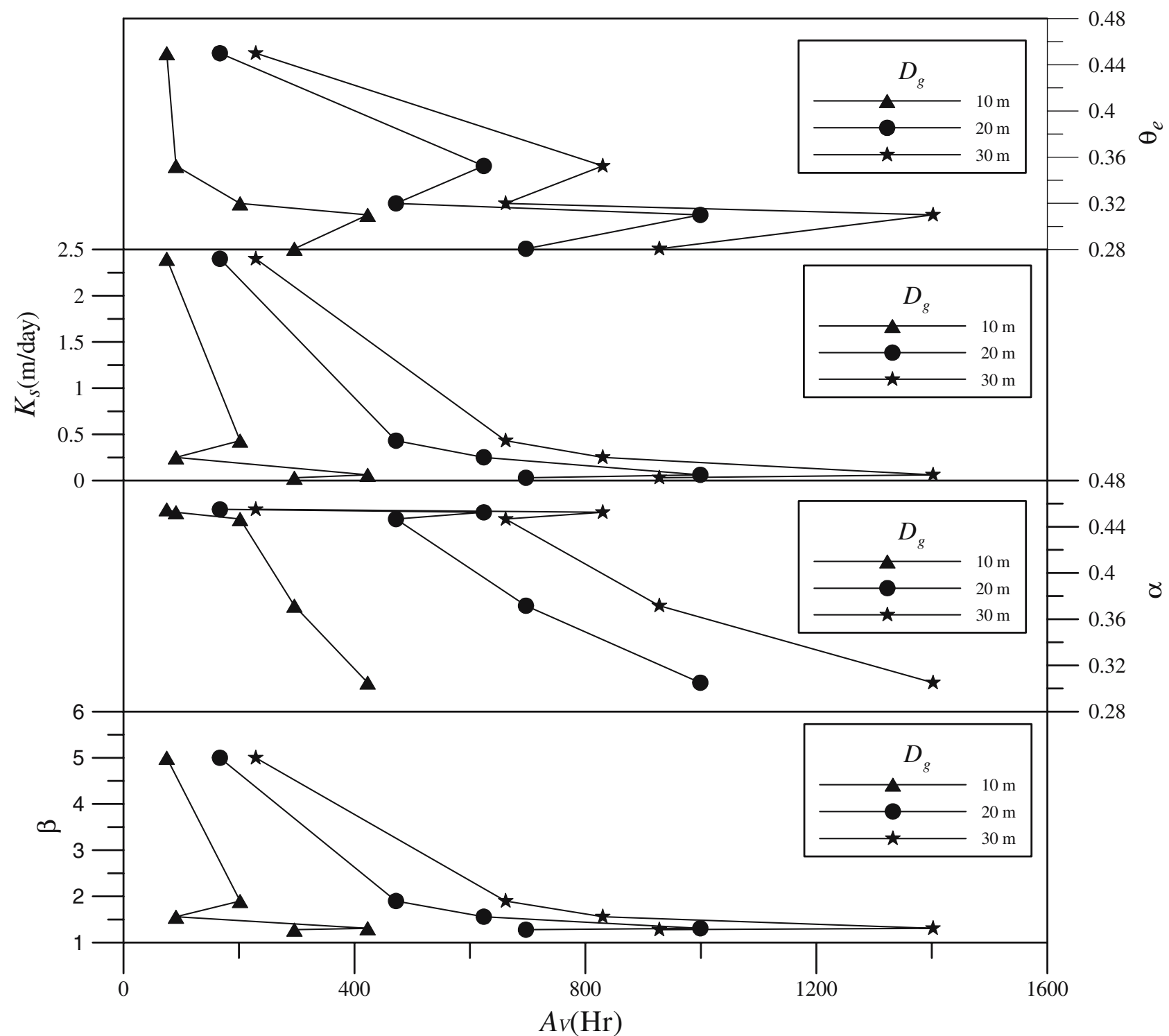

Fig. 4 Scatter plots of factors vs. arrival time

$$
\begin{aligned}
\Delta_{A_{\mathrm{V}} D_{\mathrm{p}}}(1) & =\left|x_{A_{\mathrm{V}}}^{*}(1)-x_{D_{\mathrm{p}}}^{*}(1)\right|=0.7241 \\
\Delta_{A_{\mathrm{V}} D_{\mathrm{g}}}(1) & =\left|x_{A_{\mathrm{V}}}^{*}(1)-x_{D_{\mathrm{g}}}^{*}(1)\right|=0.2579 \\
\Delta_{A_{\mathrm{V}} \theta_{\mathrm{e}}}(1) & =\left|x_{A_{\mathrm{V}}}^{*}(1)-x_{\theta_{\mathrm{e}}}^{*}(1)\right|=0.5510 \\
\Delta A_{\mathrm{V}} K_{\mathrm{S}} & (1)=\left|x_{A_{\mathrm{V}}}^{*}(1)-x_{K_{\mathrm{S}}}^{*}(1)\right|=0.7107 \\
\Delta_{A_{\mathrm{V} \alpha}}(1) & =\left|x_{A_{\mathrm{V}}}^{*}(1)-x_{\alpha}^{*}(1)\right|=0.7241 \\
\Delta_{A_{\mathrm{V}} \beta}(1) & =\left|x_{A_{\mathrm{V}}}^{*}(1)-x_{\beta}^{*}(1)\right|=0.7160 .
\end{aligned}
$$

The same method was used for each of the $k$ values $(k=1, \ldots, 45)$ and Fig. 6 plots the results of all deviation sequences. According to Fig. 6, $\Delta_{\max }$ and $\Delta_{\min }$ are 0.9815 and 0.0 , respectively. These $\Delta_{\max }, \Delta_{\min }$ and the distinguishing coefficient $\xi$ (set to 0.5 ) were substituted into Eq. 7 to yield the grey relational coefficient. Figure 7 displays the results. Finally, the grey relational coefficients were averaged under equal weighting conditions using Eq. 8 to obtain the grey correlation grade. Table 3 presents the grey correlation grade of the reference sequence $x_{A_{\mathrm{V}}}^{*}(k)$ and the comparability sequence $x_{i}^{*}(k), i=D_{\mathrm{g}}, D_{\mathrm{p}}, \theta_{\mathrm{e}}, K_{\mathrm{S}}, \alpha, \beta$. Resorting the grey correlation grade in order of magnitude, as shown in the Table 3 , yields $\Gamma\left(A_{\mathrm{V}}, \alpha\right)>\Gamma\left(A_{\mathrm{V}}, D_{\mathrm{g}}\right)>\Gamma\left(A_{\mathrm{V}}, \theta_{\mathrm{e}}\right)>$ $\Gamma\left(A_{\mathrm{V}}, D_{\mathrm{p}}\right)>\Gamma\left(A_{\mathrm{V}}, K_{\mathrm{S}}\right)>\Gamma\left(A_{\mathrm{V}}, \beta\right)$. Accordingly, the order of importance of the factors that affect the arrival time of the recharge water at the groundwater table was $\alpha, D_{\mathrm{g}}, \theta_{\mathrm{e}}, D_{\mathrm{p}}, K_{\mathrm{S}}, \beta . D_{\mathrm{g}}, \theta_{\mathrm{e}}, D_{\mathrm{p}}$ and $K_{\mathrm{S}}$ are interpreted as the displacement of the recharge water, the capacity of the soil to store water, the potential for the movement of recharge water, and the ability of the soil material to transport water, respectively. Therefore, if a site can recharge to groundwater quickly, then the sites' displacement of recharge water, the capacity the soil to 


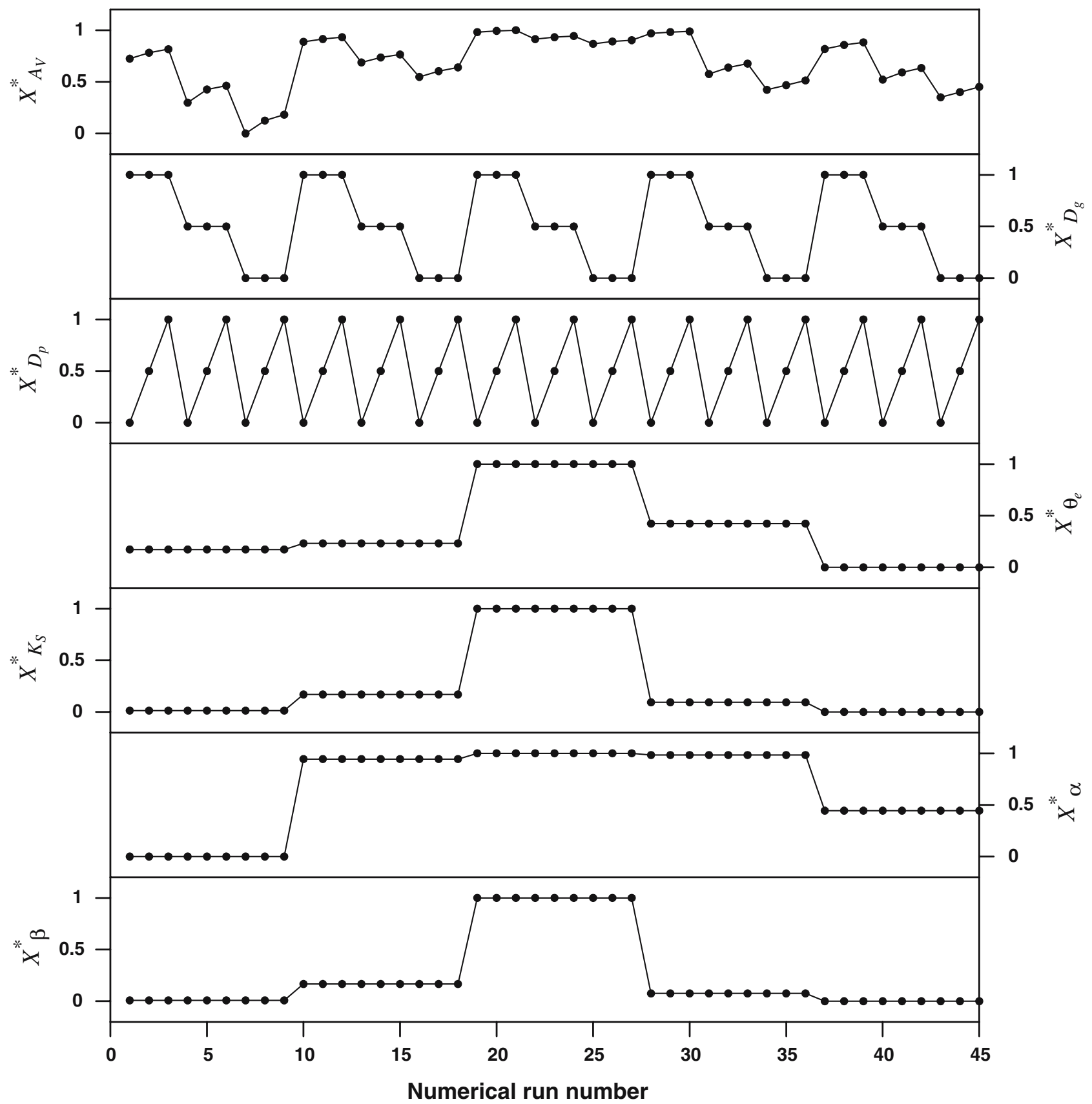

Fig. 5 Dimensionless sequence following preprocessing of data

store water, the potential for recharge water movement and the ability of the soil material to transport water must be evaluated in that order.

Figures 2 and 4 show that a small $D_{\mathrm{g}}$, a large $\theta_{\mathrm{e}}$, a large $D_{\mathrm{p}}$ and a large $K_{\mathrm{S}}$ promote the rapid recharge of water. Table 3 indicates that $\alpha$ is the factor that most strongly affects the arrival time. A large $\alpha$ is typical of sands or well-structured soils and indicates a large change in water content with a small change of heads. Accordingly, the artificial pond water infiltrates easily through the soil with high $\alpha$. Moreover, the result reveal that the hydraulic conductivity is not the most important factor in determining the arrival time. Again, an incorrect decision may be made if an engineer searches for a site for an artificial recharge pond based on only the magnitude of hydraulic conductivity.

\section{Application}

\subsection{Study area}

Yun-Lin is located in the southern part of the alluvial fan of the Cho-Shui River (Fig. 8). The area is enclosed 


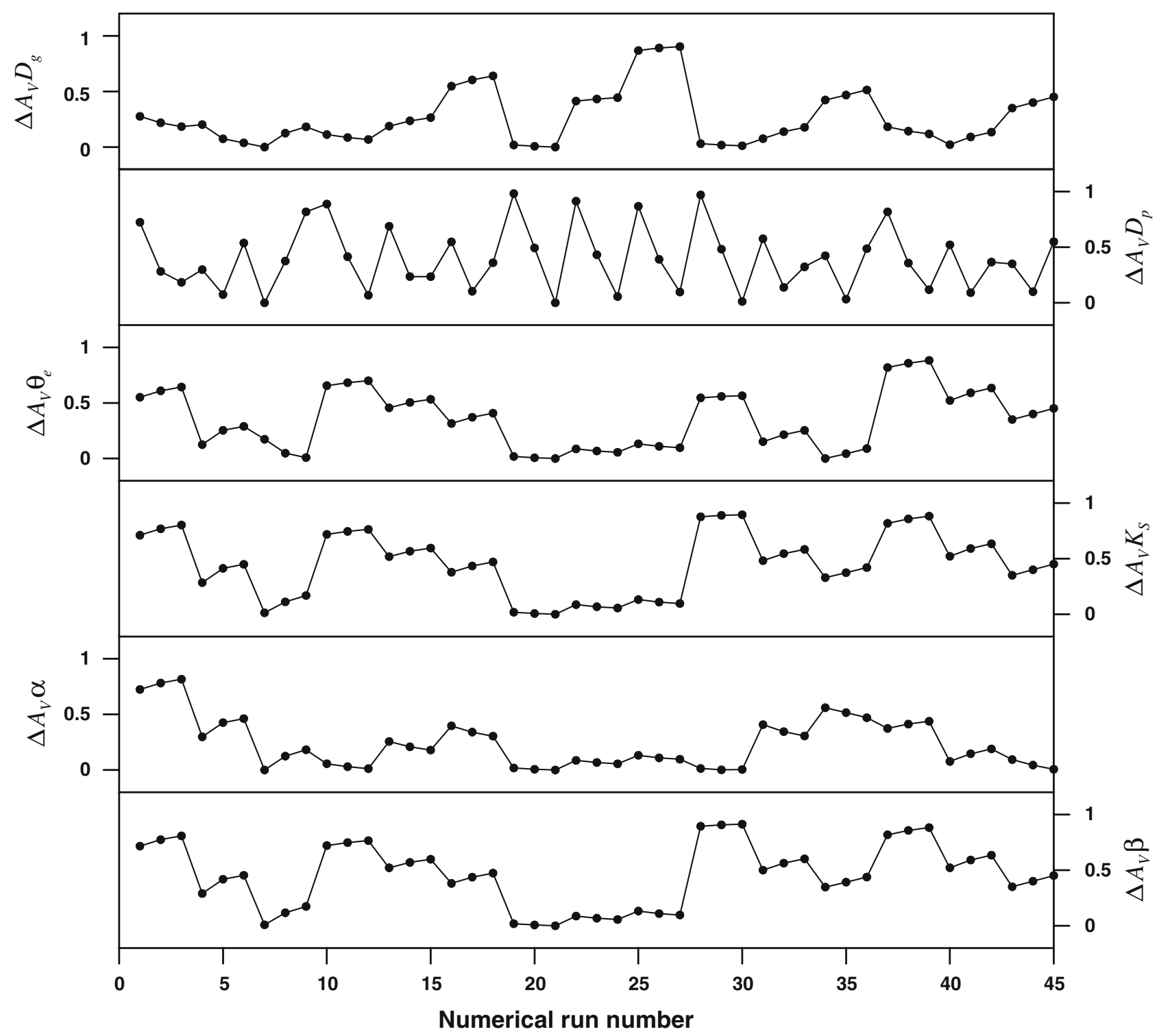

Fig. 6 Deviation sequence

by the Taiwan Strait to the west, the Central Mountain to the east, the Cho-Shui River to the north, and the Pei-Kong River to the south. The area is approximately $1,000 \mathrm{~km}^{2}$, and extends $48 \mathrm{~km}$ from east to west and $24 \mathrm{~km}$ from north to south. Large gravels and cobble were deposited on the east side; near the coast, thick layers of clay and fine sand dominate. In the middle zone, the gravel layers are interbedded with sand and clay. WRA (1999) divided the groundwater basin of Yun-Lin area into layers stacked in the vertical direction. In the coastal area, five layers of impermeable aquitard and four layers of aquifer are present. In the middle area, three layers of impermeable aquitard and four layers of aquifer are present. On the eastern side, only a single layer of the unconfined aquifer is present.
Figure 9 displays the distribution of layers and their thickness.

The conventional source of revenue in the area is agricultural product. However, the average income of farmers in this region is considerably below that of workers in other sectors, because the industrial sector has recently seen rapid growth. Accordingly, many farmers have converted their farmlands into aquacultural operations and demand large amounts of water to boost earnings. Illegal pumping wells have been densely placed along the coastal area. The wells continuously extract groundwater from the aquifer to meet aquacultural demand and have caused seriously adverse effects, such as land subsidence, seawater intrusion and environmental deterioration. Over the past two decades, 


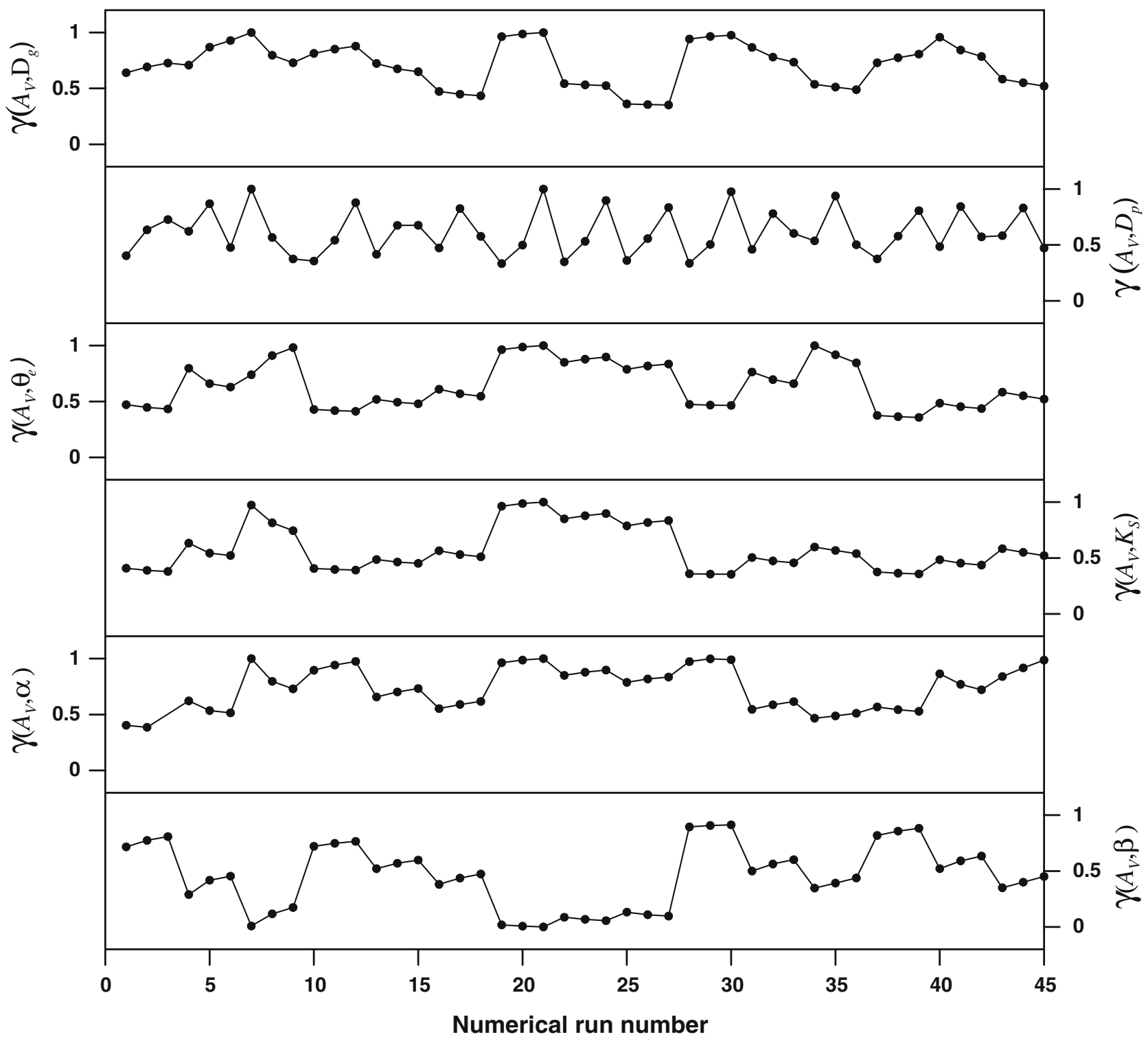

Fig. 7 Calculated grey correlation coefficients

around $610.4 \mathrm{~km}^{2}$ of the Yun-Lin plain has suffered from land subsidence. The cumulative land subsidence exceeded $215 \mathrm{~cm}$ from 1985 to 2002 . Therefore, suitable sites must be selected for artificial recharge to reduce the rate of land subsidence (WRA 1998).

Table 3 Grey correlation grade determined from the average of grey relational coefficients with equal weightings, based on $A_{\mathrm{V}}$ as a reference series

\begin{tabular}{llllllll}
\hline Hydrogeological & $\alpha$ & $D_{\mathrm{g}}$ & $\theta_{\mathrm{e}}$ & $D_{\mathrm{p}}$ & $K_{\mathrm{S}}$ & $\beta$
\end{tabular}
parameters

$\begin{array}{lllllll}\text { Grey correlation } & 0.7324 & 0.7114 & 0.6438 & 0.6143 & 0.5769 & 0.5747\end{array}$ grade

\subsection{Data collection}

Six hydrogeological factors, $D_{\mathrm{g}}, D_{\mathrm{p}}, \theta_{\mathrm{e}}, K_{\mathrm{S}}, \alpha$ and $\beta$, are considered herein this work. $D_{\mathrm{p}}$ is assigned to $3 \mathrm{~m}$. Other factors are obtained from the literature. The soil parameters are taken from Chen (2002), who measured the unsaturated hydraulic conductivity of 20 soil samples over the Yun-Lin plain, as shown in Fig. 8. They are fitted using the Brooks-Corey model (Brooks and Corey 1964). The definition of parameters in the Mualem-van Genuchten model (van Genuchten 1980) is not fully consistent with the parameters of the BrooksCorey model, so parameters must be transformed between the two models. A parameter transformation developed by Hubert et al. (1996) is adopted and expressed as follows. 
Fig. 8 Geographical location of Yun-Lin plain and sampling sites of the unsaturated soil experiment

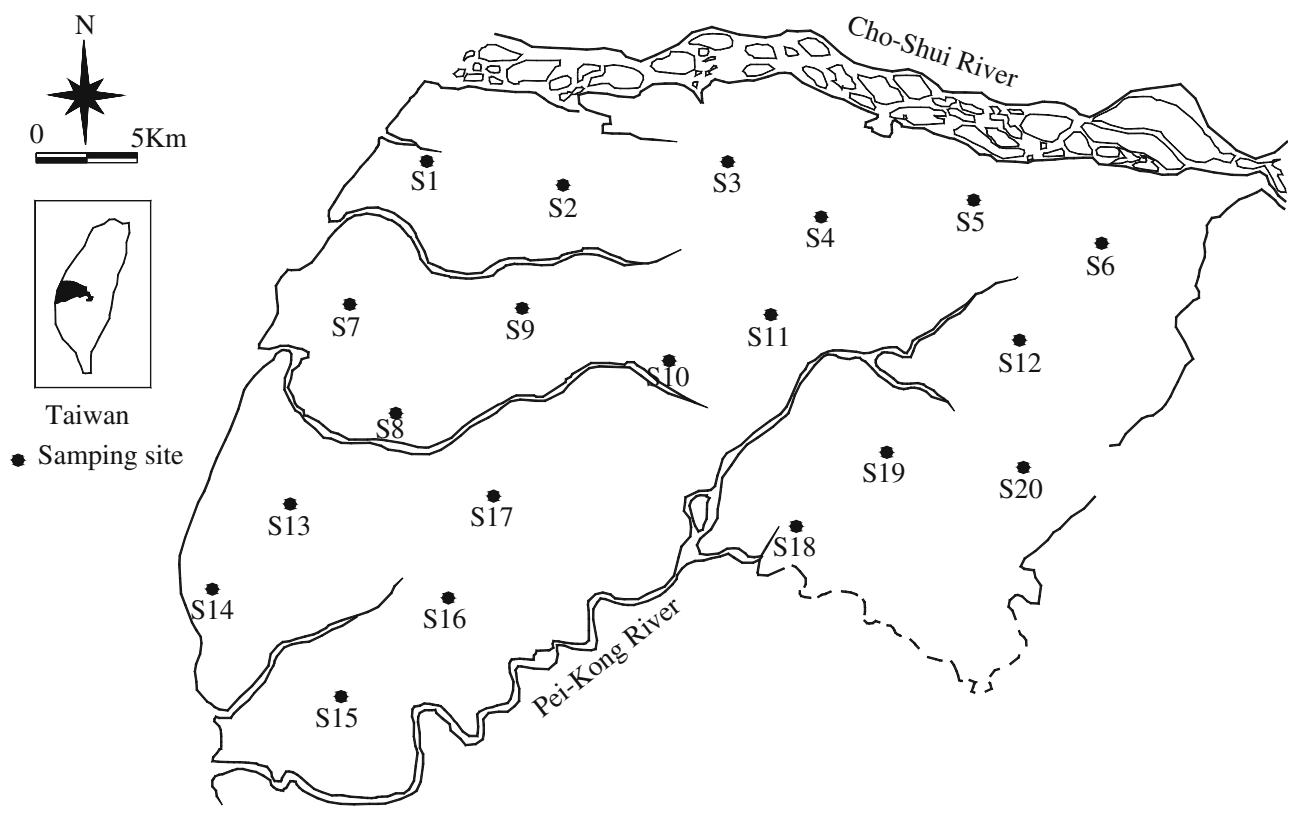

$1-\frac{1}{\beta}=\frac{2}{p-1}$,

$\frac{1}{\alpha}=h_{\mathrm{ce}} \frac{2 p(p-1)}{p+3}\left(\frac{55.6+7.4 p+p^{2}}{147.8+8.1 p+0.092 p^{2}}\right)$,

where $h_{\text {ce }}$ is the entry pressure; $\lambda$ is the fitting parameter in the Brooks-Corey model, and $p=2 / \lambda+3$. At the same time, the depths of groundwater below the surface must be measured at the sampling sites. No observation well is present at the sampling site, so the values of $D_{\mathrm{g}}$ in the sampling sites were determined by interpolation from the values of $D_{\mathrm{g}}$ in the 42 observation wells that were constructed in Yun-Lin plain by WRA (2002). The $D_{\mathrm{g}}$ at an observation well was calculated by subtracting the daily average level form the level at the top of observation well. Table 4 lists the values of $D_{\mathrm{g}}, D_{\mathrm{p}}, \theta_{\mathrm{e}}$, $K_{\mathrm{S}}, \alpha$ and $\beta$ in the 20 sampling sites.

\subsection{Evaluation of artificial recharge site}

An index must be defined for comparison among the sampling sites to identify an optimal site for artificial recharge from all of the sampling sites. An index, ID, was defined as follows;

$\mathrm{ID}=\sum_{i=1}^{m} W_{i} \times \mathrm{FC}_{i}$

where $W_{i}$ is the weight of factor $i$ FC $\mathrm{FC}_{i}$ is the observed value of factor $i$, and $m$ is the number of influential factors.

In this work, the depth of pond water was set to $3 \mathrm{~m}$ at all sampling sites. Hence, this factor has the same effect on the movement of recharge water at all sampling sites. Accordingly, the number of factors $m$ is reduced to five. The grey correlation grade can be used to represent the grade of the factor's contribution to the movement of the recharge water, so the grey correlation grade of the influence factor was taken as the weight in Eq. 12. The observed value yielded the normalized value of the influence factor. Equation 4 was used to determine the factors in the sequence $\theta_{\mathrm{e}}, K_{\mathrm{S}}, \alpha, \beta$ and $D_{\mathrm{p}}$ because these factors are "the-larger-the-better'. Equation 5 was used to evaluate the factor sequence $D_{\mathrm{g}}$, because this factor is "the-smaller-the-better". Figure 10 presents the resulting indicator values at the sampling sites.

The index value supported the classification of good sites, normal sites and poor sites. Good sites have index values from 2 to 3 ; normal sites have index values from 1 to 2 ; poor sites have index values from 0 to 1 . Figure 10 shows that sites S9, S12 and S13 are good sites; site S20 is a poor site, and the others are normal sites.

If the suitable area for artificial recharge is not the sampling site, then it can be identified by constructing a contour map of index values. Figure 11 plots a contour map of the distribution of index values, based on values at 20 sampling sites. The shading represents the value of index. As the gray color changes from dark to light, the index increases from small to large. A region with a large value indicates is suitable for artificial recharge. If a critical value of 1.6 is set which is about the mean value of the normal site, then the three areas A, B and C, displayed in Fig. 11, are areas in which the index values exceed the critical value. Therefore, those areas are considered to be potentially good for artificial recharge in the Yun-Lin plain. Areas B and C are near the coast, and the recharge water from these two areas can only reach the upper aquifer. Area $A$ is in the upper plain, and can directly recharge water to the lower layer of the aquifer. Area A is regarded as more suitable for groundwater recharge than area $\mathrm{B}$ and $\mathrm{C}$. 


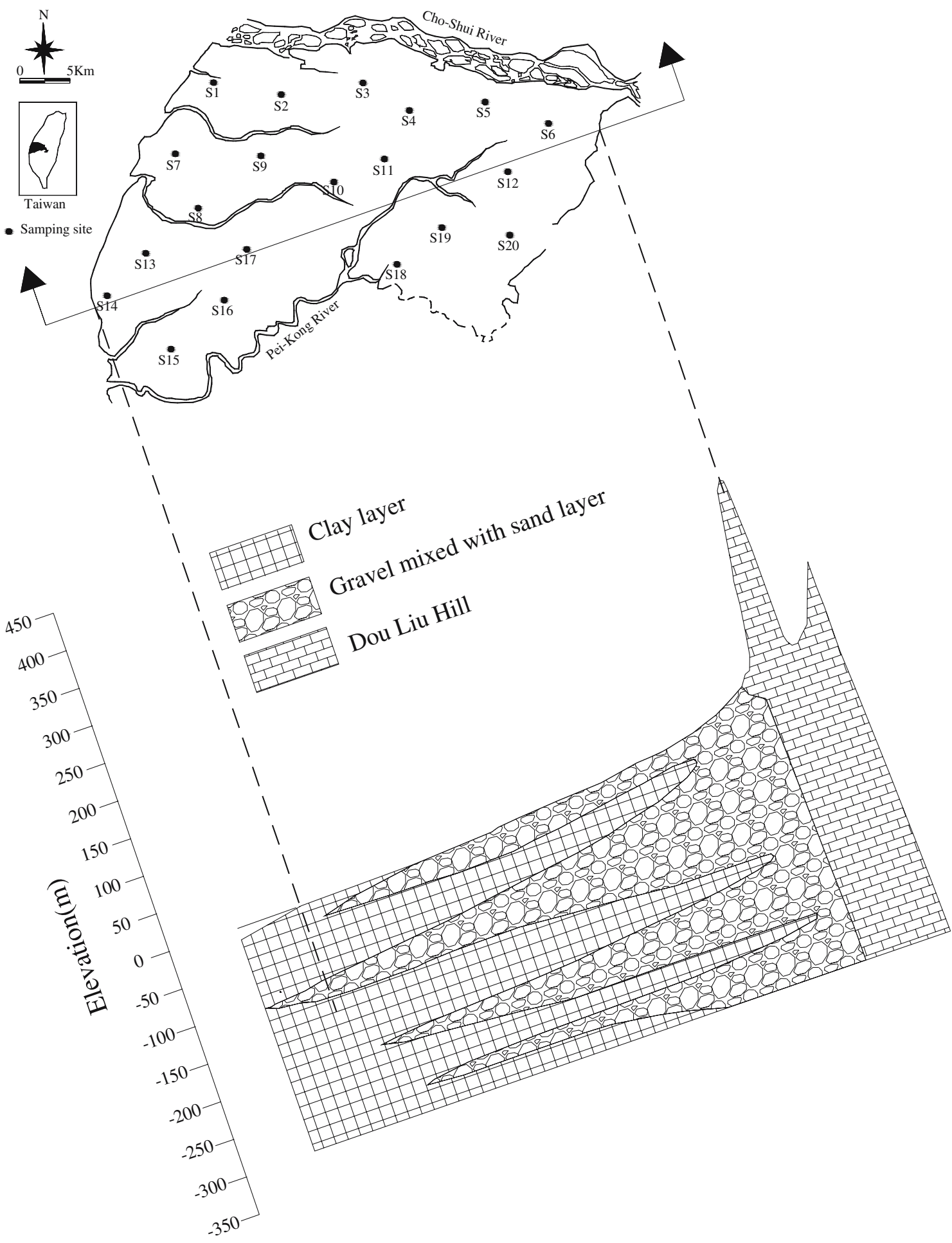

Fig. 9 Hydrogeological profile of Yun-Lin

\section{Conclusion}

Artificial recharge is a practical approach for increasing groundwater storage in an aquifer. The efficiency of artificial recharge is related to site-specific hydrogeological factors. Therefore, the relationship between the hydrogeological factors and the movement of the recharge water front must be investigated to identify a suitable site for artificial recharge. A variable satu- 
Table 4 Soil parameters and depth of groundwater table below the surface at the sampling sites

\begin{tabular}{llllllr}
\hline $\begin{array}{l}\text { Number of } \\
\text { sampling site }\end{array}$ & $\alpha$ & $\beta$ & $\theta_{\mathrm{e}}$ & $K_{\mathrm{S}}(\mathrm{m} / \mathrm{h})$ & $D_{\mathrm{p}}(\mathrm{m})$ & $D_{\mathrm{g}}(\mathrm{m})$ \\
\hline S1 & 0.0915 & 1.4500 & 0.3000 & 0.00201 & 3 & 18.75 \\
S2 & 0.2479 & 1.1500 & 0.3500 & 0.04140 & 3 & 4.99 \\
S3 & 0.6347 & 1.6200 & 0.2700 & 0.00445 & 3 & 8.79 \\
S4 & 0.1228 & 1.3100 & 0.3700 & 0.00173 & 3 & 4.84 \\
S5 & 0.5096 & 1.4200 & 0.3600 & 0.05044 & 3 & 6.16 \\
S6 & 0.6498 & 1.4600 & 0.2500 & 0.02526 & 3 & 17.17 \\
S7 & 0.3017 & 1.6400 & 0.3700 & 0.00401 & 3 & 9.39 \\
S8 & 0.3449 & 1.3200 & 0.3000 & 0.00226 & 3 & 16.53 \\
S9 & 0.6688 & 1.6300 & 0.3800 & 0.12577 & 3 & 3.13 \\
S10 & 0.2194 & 1.4000 & 0.3800 & 0.00123 & 3 & 4.75 \\
S11 & 0.1495 & 1.2800 & 0.3300 & 0.04765 & 3 & 12.37 \\
S12 & 1.0036 & 1.9500 & 0.1800 & 0.02472 & 3 & 6.55 \\
S13 & 0.8312 & 1.5100 & 0.4100 & 0.06488 & 3 & 20.01 \\
S14 & 0.4311 & 2.0000 & 0.2500 & 0.01332 & 3 & 6.08 \\
S15 & 0.3159 & 1.4200 & 0.2100 & 0.05682 & 3 & 21.19 \\
S16 & 0.4909 & 1.6600 & 0.2200 & 0.02198 & 3 & 23.7 \\
S17 & 0.3391 & 1.3300 & 0.2800 & 0.00255 & 3 & 16.76 \\
S18 & 0.4587 & 1.4800 & 0.3200 & 0.01096 & 3 & 3.76 \\
S19 & 0.4682 & 1.4400 & 0.4000 & 0.00725 & 3 & 5.93 \\
S20 & 0.3354 & 1.5900 & 0.1300 & 0.01627 & 3 & 41.65 \\
\hline
\end{tabular}

rated groundwater model, FEMWATER, was used herein to simulate the wetting front of recharge water infiltration from the artificial recharge pond and to determine the arrival time of wetting front contacts with the groundwater table. The relationship between the arrival time and the hydrogeological factors used in FEMWATER was analyzed by the grey correlation method.
The six factors used in the FEMWATER were $D_{\mathrm{g}}$, $D_{\mathrm{p}}, \theta_{\mathrm{e}}, K_{\mathrm{S}}, \alpha$ and $\beta . D_{\mathrm{g}}, D_{\mathrm{p}}, \theta_{\mathrm{e}}$ and $K_{\mathrm{S}}$ represent the displacement of the recharge water, the capacity of the soil to store water, the potential for movement of the recharge water and the ability of the soil to transport water, respectively. Forty-five cases were simulated to obtain the corresponding arrival time. The grey correlation method was used to analyze the relationships between arrival time and the above six factors. The results indicate that the order of importance of the factors to the arrival time, is in the order $\alpha, D_{\mathrm{g}}, \theta_{\mathrm{e}}, D_{\mathrm{p}}, K_{\mathrm{S}}$, $\beta$. The hydraulic conductivity is not the most important factor in determining the arrival time. An incorrect decision may be made if an engineer selects a site for artificial recharge based only on hydraulic conductivity. Additionally, the results provide a rule for selecting an artificial recharge site. The factors $\alpha, D_{\mathrm{p}}, \theta_{\mathrm{e}}, K_{\mathrm{S}}$ and $\beta$ can be compared in that order to locate a suitable site for artificial recharge. High factor values indicate suitability for artificial recharge, except for factor $D_{\mathrm{g}}$. Factors $\alpha$ and $\beta$ are determined by fitting to an unsaturated soil characteristic curve. However, evaluating $\alpha$ and $\beta$ is time-consuming and expensive. If the project fund or time is limited, factors should be compared in order $D_{\mathrm{g}}, \theta_{\mathrm{e}}, D_{\mathrm{p}}, K_{\mathrm{S}}$ to select an optimal site for artificial recharge.

The method is also applied to determine a suitable site for artificial recharge in the Yun-Lin plain. The results of grey correlation analysis show that sampling sites S9, S12 and S13 are more suitable for artificial recharge than the others sites. Moreover, contour mapping of the distribution of index values reveals cases

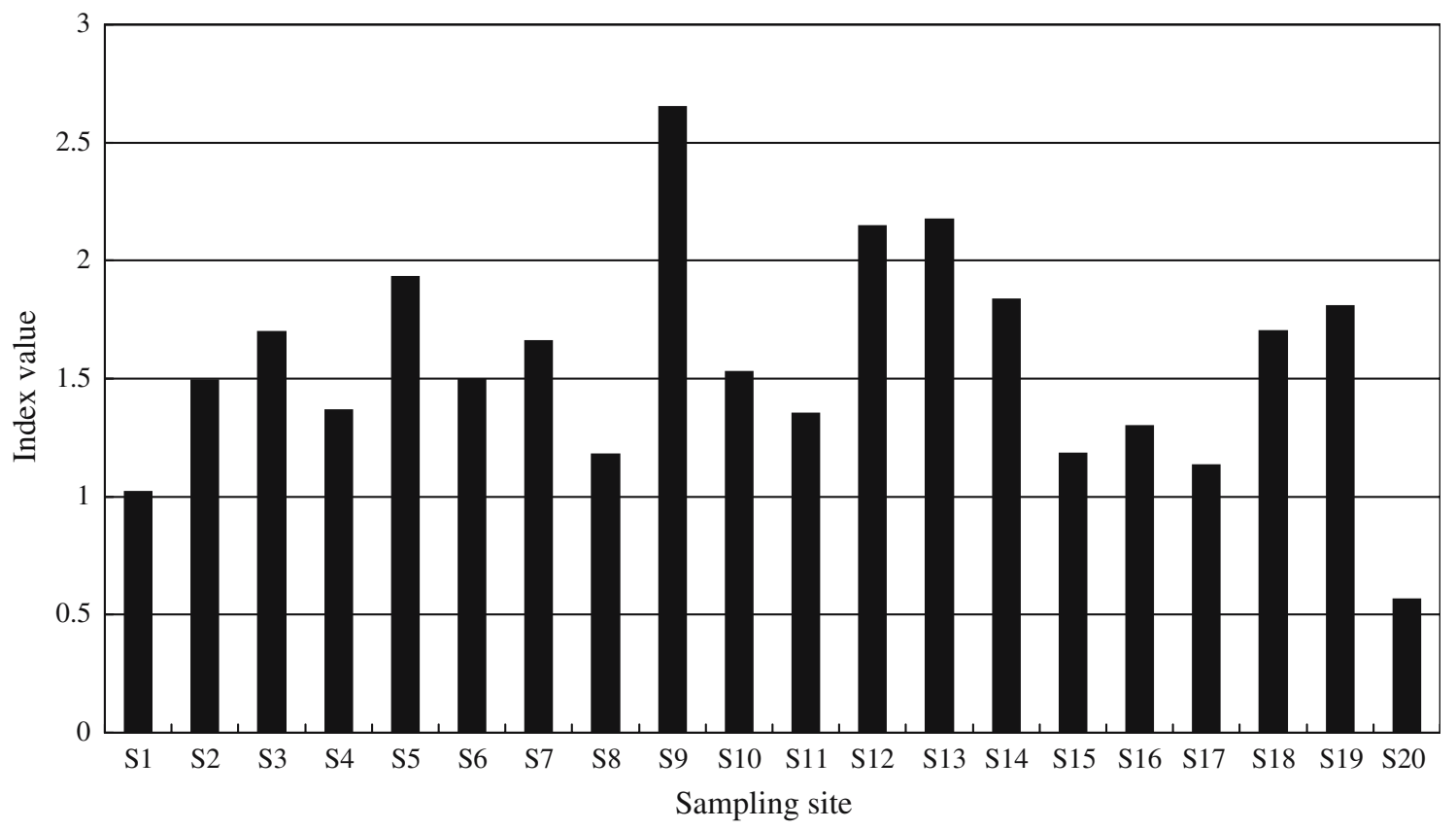

Fig. 10 Values of index at sampling site 
Fig. 11 Distribution of index values over Yun-Lin

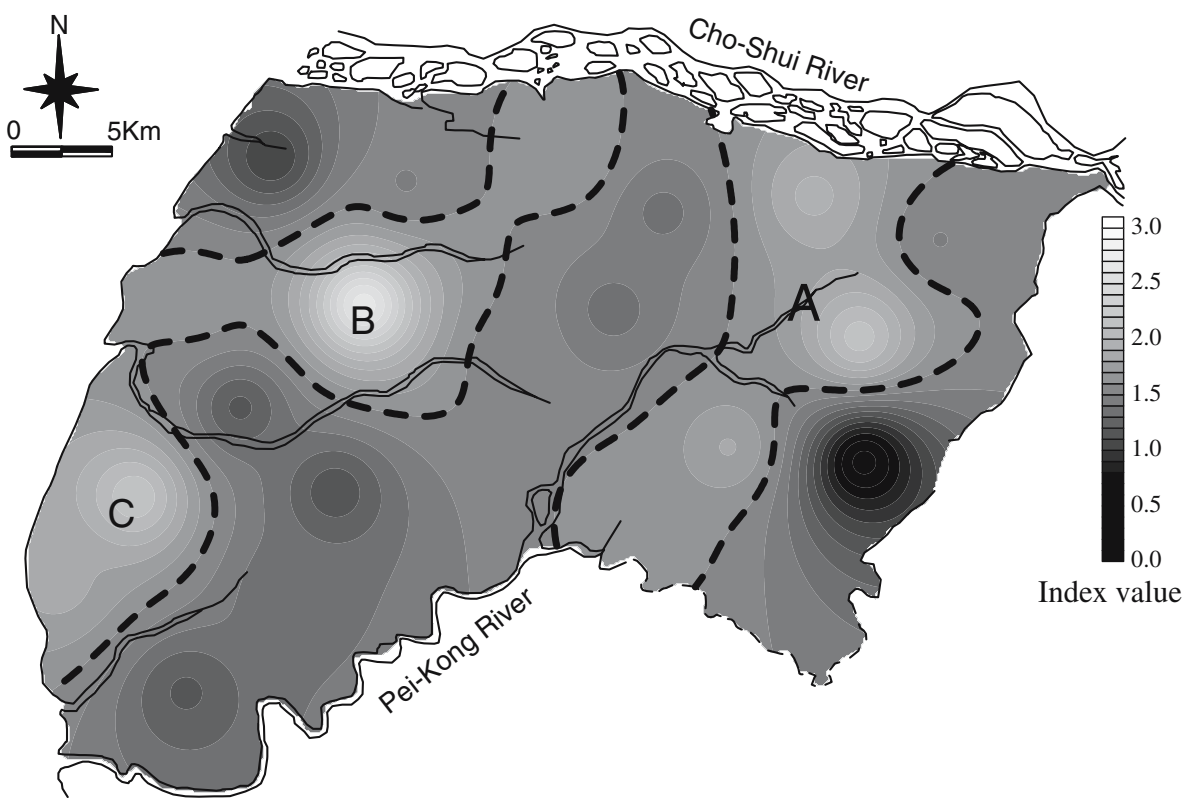

in which the area of artificial recharge falls outside the sampling sites. The results demonstrate that three areas are the suitable for artificial recharge. Two areas B and $\mathrm{C}$ are near the coast, where infiltrated water can only recharge to the upper aquifer, while area $\mathrm{A}$ is in the upper plain, where the infiltrated water can recharge directly to the lower aquifer. Area $\mathrm{A}$ is considered to be better suited to groundwater recharge than areas $\mathrm{B}$ and $\mathrm{C}$ in the Yun-Lin plain.

Acknowledgements We would like to thank the National Science Council of ROC (Taiwan) for financially supporting this research under Contract No. NSC 91-2313-B-127-002.

\section{References}

Bouwer H (1996) Issue artificial recharge. Water Sci Tech 33:381390

Bouwer H (2002) Artificial recharge of groundwater: hydrogeology and engineering. Hydrogol J 10:121-142

Brooks RH, Corey AT (1964) Hydraulic properties of porous media affecting fluid flow. J Irrig Drain Div Am Soc Civ Eng 92(IR2):61-88

Chang NB (2005) Sustainable water resources management under uncertainty. Stoch Environ Res Risk Assess 19:97-98

Chang TC, Lin SJ (1999) Grey relation analysis of carbon dioxide emissions from industrial production. $\mathbf{J}$ Environ Manag $56: 247-257$

Chapman TG, Malone RW (2002) Comparison of models for estimation of groundwater recharge, using data from a deep weighing lysimeter. Math Comput Simul 59:3-17

Chen JF (2002) Analysis and application of a water budget model in the unsaturated zone. PhD Thesis, National Cheng Kung University, Tainan

Cook PG, Robinson NI (2002) Estimating groundwater recharge in fractured rock from environmental $3 \mathrm{H}$ and $36 \mathrm{Cl}$, Clare Valley, South Australia. Water Resour Res 38. DOI 10.1029/ 2001WR000772

van Dam J C, Feddes RA (2000) Numerical simulation of infiltration, evaporation and shallow groundwater levels with the Richards equation. J Hydrol 233:72-85
Deng JL (1989) Introduction to the grey system theory. J Grey Syst 1:1-24

Deng JL (1996) Fundamental methods on grey system. Hua-Zhong University of Science and Technology Press, Wu-Han

El-Hames AS, Richards KS (1995) Testing the numerical difficulty applying Richards' equation to sandy and clayey soils. J Hydrol 167:381-391

EMRL (2003) Groundwater modeling system tutorials volume I IV. Brigham Young University, UT

Eriksson E, Khunakasem V (1969) Chloride concentration in groundwater, recharge rate and rate of deposition of chloride in the Israel coastal plain. J Hydrol 7(2):178-197

Finch JW (1998) Estimating direct groundwater recharge using a simple water balance model-sensitivity to land surface parameters. J Hydrol 211:112-125

Fung CP (2003) Manufacturing process optimization for wear property of fiber reinforced polybutlene terephthalate composite with grey relation analysis. Wear 254:298-306

Gau HS, Chen JS, Peng JK, Hsieh SY (2001) The influence of hydraulic conductivity, pond water depth and ground water depth on artificial groundwater recharge (in Chinese). Taiwan Water Conserv 149:46-54

van Genuchten MT (1980) A close-form equation for predicting the hydraulic conductivity of unsaturated soils. Soil Sci Soc Am J 44:892-898

Giao PH, Phien-Wej N, Honjo Y (1999) FEM quasi-3D modeling of responses to artificial recharge in the Bangkok multiaquifer system. Environ Model Softw 14:141-151

Hodnett MG, Tomasella J (2002) Marked differences between van Genuchten soil water-retention parameters for temperate and tropical soils: a new water retention pedo-transfer functions developed for tropical soils. Geoderma 128:155-180

Hubert J, Meyer PD, Nachabe M, Touma J, van Genuchten MT, Lenhard RJ (1996) Parameter equivalence for the BrooksCroey and van Genuchten soil characteristics: preserving the effective capillary drive. Water Resour Res 32(5):1251-1258

Kao C, Bouarfa S, Zimmer D (2001) Steady state analysis of unsaturated flow above a shallow water-table aquifer drained by ditches. J Hydrol 250:122-133

Liang RH (1999) Application of grey relation analysis to hydroelectric generation scheduling. Electr Power Energy Syst 21:357-364

Lin HC, Richards DR, Yeh GT, Cheng JR, Cheng HP, Jones NL (1997) FEMWATER: a three-dimensional finite element computer model for simulating density-dependent flow and transport in variably saturated media, Technical Report CHL-97-12, U.S. Army Corps of Engineer, 151pp

Luckner L, van Genuchten MTh, Nielsen DR (1989) A consistent set of parametric models for the two phase flow of immiscible fluids in the subsurface. Water Resour Res 25:2187-2193 
Parlange JY, Hogarth WL, Barry DA, Parlange MB, Haverkamp R, Ross PJ, Steenhuis TS, DiCarlo DA, Katul G (1999) Analytical approximation to the solutions of Richards' equation with applications to infiltration, ponding, and time compression approximation. Adv Water Resour 23:189-194

Ragab R, Finch J, Harding R (1997) Estimation of groundwater recharge to chalk and sandstone aquifer using simple soil models. J Hydrol 190:19-41

Rastogi AK, Pandey SN (1998) Modeling of artificial recharge b of different shapes and effect on underlying system. J Hydrol Eng $3: 62-68$

Salama RB, Tapley I, Ishii T, Hawkes G (1994) Identification of areas of recharge and disharge using Landsat-TM satellite imagery and aerial photography mapping techniques. J Hydrol 162:119-141

Saraf AK, Choudhury PR (1998) Integrated remote sensing and GIS for groundwater exploration and identification of artificial recharge sites. Int J Remote Sensing 19:1825-1841
Sukhija BS, Reddy DV, Nandakumar MV, Rama (1997) A method for evaluation of artificial recharge through percolation tanks using environmental chloride. Ground Water 35:161-165

Todd DK (1980) Groundwater hydrology. Wiley, New York, $535 \mathrm{pp}$

Warrick AW (1991) Numerical approximations of darcian flow through unsaturated soil. Water Resour Res 27:1215-1222

WRA (1998) Planning of groundwater artificial recharge on ChoShui-River alluvial. Technical Report, Water Resources Agency, Taiwan

WRA (1999) Corpus book for the reports of the entire groundwater monitoring plan-the first stage from 1992 to 1998 Technical Report, Water Resources Agency, Taiwan

WRA (2002) Hydrological year book of Taiwan, Water Resources Agency, Taiwan

Yeh YL, Chen TC (2004) Application of grey correlation analysis for evaluating the artificial lake site in Pingtung Plain, Taiwan. Can J Environ Eng 31:56-64 